\title{
Intelligent Automatic 3D Printing Machine Based on Wireless Network Communication
}

\author{
Wei Zhang, ${ }^{1}$ Xiangwen Deng, ${ }^{1}$ and Jie Cai $\mathbb{D}^{2}$ \\ ${ }^{1}$ College of Information and Intelligence Engineering, Zhejiang Wanli University, Ningbo, 315100 Zhejiang, China \\ ${ }^{2}$ School of Intelligent Manufacturing, Zhejiang Institute of Mechanical \& Electrical Engineering, Hangzhou, 310053 Zhejiang, China
}

Correspondence should be addressed to Jie Cai; caijie@zime.edu.cn

Received 23 October 2021; Revised 23 November 2021; Accepted 29 November 2021; Published 16 December 2021

Academic Editor: Deepak Kumar Jain

Copyright (c) 2021 Wei Zhang et al. This is an open access article distributed under the Creative Commons Attribution License, which permits unrestricted use, distribution, and reproduction in any medium, provided the original work is properly cited.

\begin{abstract}
With the advent of the era of big data, people have higher requirements for material and spiritual gains and happiness, and their demands for various services in the communications field are diversified. The most significant change is the $3 \mathrm{D}$ printing technology. With its unique advantages, 3D printing is gradually sweeping the world. In order to explore whether the technology or digital model based on wireless network communication can realize the automation and intelligence of 3D printing, this article applies a variety of scientific methods such as simulation experiment method, data collection method, and sample analysis method; collects samples; and simplifies the algorithm, using basic experimental methods, orthogonal experiments, and single-factor experiments to study the various influencing factors in the automatic printing process to obtain the optimal parameter combination. Experimental results show that with the support of wireless communication network hardware and data, the timeliness and quality of 3D printing can be significantly improved. These are the basis for realizing $3 \mathrm{D}$ printing automation and intelligence. Further experiments show that the wireless communication network intelligent automatic $3 \mathrm{D}$ printing machinery adjusts 3D printing parameters through wireless communication technology, combined with intelligent real-time monitoring and sensing equipment; we can find that the printing efficiency of the $3 \mathrm{D}$ printing machinery is increased by about $15 \%$, and the economic cost is saved by about $20 \%$. It basically shows the practicality of the experimental research results.
\end{abstract}

\section{Introduction}

With the development of the times and science and technology, mobile communication has penetrated into daily life [1]. People expect to be able to provide more and more services, and at the same time, they are increasingly demanding on service quality [2]. Traditional GSM and CDMA technologies cannot meet people's demand for high-speed, instant communication. It can be predicted that the transmission rate of the future communication model will increase by one to two orders of magnitude, and the development trend of wireless networks is to require high rates and higher link reliability [3]. In a wireless network, all channels are shared, and the transmitted signals may be received by nearby users or affect the transmission of others. At the same time, it also indicates that the wireless communication industry and wireless communication technology have entered an impor- tant period of rapid development, and more and more intelligent terminal devices continue to access wireless networks [4].

$3 \mathrm{D}$ printing (3D printing) technology is an emerging additive manufacturing technology that is rapidly developing and expanding in the manufacturing industry, and is hailed as "manufacturing technology with industrial revolution significance." With its unique advantages, $3 \mathrm{D}$ printing is gradually sweeping the world. $3 \mathrm{D}$ printing benefits from the integration of cutting-edge technologies in multiple disciplines, making it widely used in aerospace, national defense, biomedicine, government, medical equipment, high technology, education, manufacturing, automobiles, motorcycles, and home appliances [5]. The development prospects are very broad. But how can a perfect connection between the wireless network and the printing device be achieved? Whether it is necessary to improve and adjust the current 
equipment to adapt to the adjustment of wireless communication remains to be discussed. Based on the wireless communication network, can 3D printing be truly intelligent and automated? These are all problems that need to be practiced and solved [6]. In order to explore the automation and intelligence of $3 \mathrm{D}$ printing based on wireless network communication technology, my country will continue to vigorously promote economic growth in the face of the complex and changeable international environment and the arduous task of domestic economic reform and development at present and in the future. With the transformation of the model, the internal and external environment of the manufacturing industry will also undergo important changes. The new generation of information technology and manufacturing will crossdevelop. Traditional production methods, production modes, industrial chains, etc. will be greatly affected. The new generation of manufacturing technology will change these, and digital and intelligent manufacturing technology will form and lead future trends and directions.

In 2018, when Ibrahimov et al. established connections and provided multimedia services, the indicators of intelligent communication networks were analyzed on the basis of the architecture concept NGN (Next-Generation Network). The effectiveness of the intelligent communication network is studied, and on this basis, a mathematical model of business traffic using the INAP protocol is proposed. On the basis of obtaining the analytical expression of the model, the performance index of the intelligent communication network can be estimated. However, follow-up research deviates from the main point [7]. Au et al. find that microfloppy automation automatically routing, dispensing, mixing, and separating liquids through microchannels is often still a slow-propagating technology because equipment manufacturing requires advanced equipment and the use of this technology requires expert operators. Au et al. found that integrating microfloppy automation in the device involves specialized multilayer and bonding methods. They believe that stereo lithography is an assembly-free 3D printing technology that is becoming an effective alternative to rapid prototyping of biomedical device method. They describe fluid valves and pumps that can be stereoscopically printed on optically transparent, biocompatible plastic and integrated in microfloppy devices at low cost. User-friendly fluid automation equipment can be printed and used, replacing expensive robotic pipettes or tedious manual delivery by nonengineers. They operate these designs as digital modules into new, extended-function devices. Printing these devices requires only digital files and electronic access to the printer [8].

How to adjust the $3 \mathrm{D}$ printing machinery in real time and accurately with the help of the wireless network communication technology, use real-time sensors to monitor and scan the printing, adjust the parameters of the printing parameters in real time, and find a new direction for the further development and breakthrough of 3D printing technology remains to be elucidated. The purpose of this article is to study the use of 3D printing technology to build the technology or digital model based on the wireless network commu- nication technology to improve the efficiency of mechanical manufacturing and achieve automation and intelligence. By constructing an experimental model, the error size during $3 \mathrm{D}$ printing is analyzed and corrected, and the process parameters during printing are analyzed. Through the wireless network communication to adjust the basic parameters such as layer thickness, printing speed, and temperature, the basic experimental methods, orthogonal experiments, and single-factor experiments are used to study each influencing factor during automatic printing to obtain the optimal parameter combination. Experiments show that with the support of the hardware and data of the wireless network communication, the timeliness and quality of 3D printing can be significantly improved. These are the basis for realizing $3 \mathrm{D}$ printing automation and intelligence.

\section{Proposed Method}

2.1. Wireless Network Communication Technology Framework. In the era of data, people's pursuit of a better life continues to increase, and the demand for ultra-high-speed, wide-area, full-coverage, and low-latency information exchange in wireless communication networks is correspondingly increased. A large number of wireless communication devices and smart industries are connected to wireless networks. The number of wireless communication equipment continues to soar, and the scale of communication networks continues to expand, resulting in a rapid increase in the energy consumption of communication networks, a shortage of spectrum resources, and a sharp increase in air pollutants generated by the energy consumption of wireless communication networks. How to make full use of existing energy, better solving the spectrum crisis, reducing carbon footprint and air pollutant emissions, and providing users with higher network capacity and better experience rate have become the focus of many scientific research works. Here are four more commonly used communication models.

\section{(1) Cellular communication model}

In the wireless communication network downlink communication link scenario, the wireless communication network is divided into several cells according to the number of base stations. It may be possible to set the total number of base stations in the wireless communication model as $n$, and all intelligent terminals and mobile devices in the model adopt single-root fully open wireless antenna for sending and receiving information. If the model area is divided into regular polygon cells of the same size and area, each base station is located in the center of the cell, as shown in Figure 1.

It can be seen from Figure 1 that in the downlink communication link of the cellular network, the OFDMA technology is used to divide the communication bandwidth into subcarriers with equal frequency bandwidths and allocate them to the user access network.

In the communication link, assuming that the $u$ th user in a certain area transmits information with the base station 


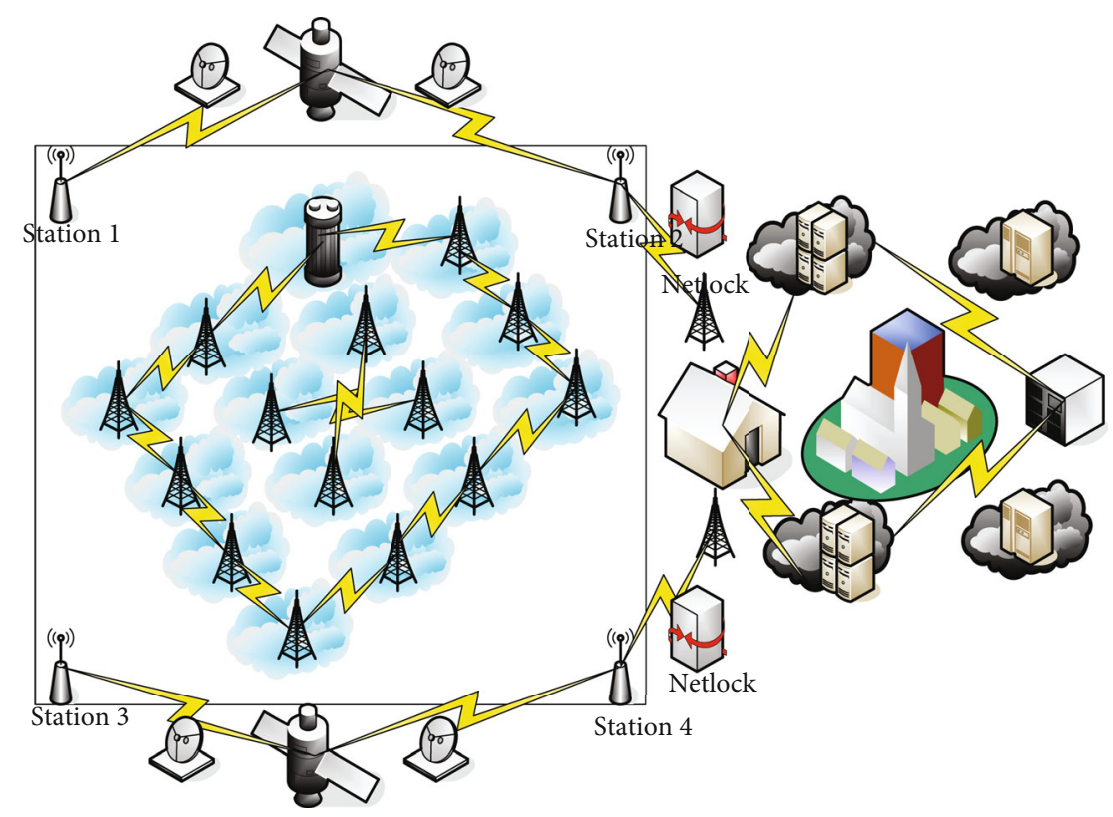

FIGURE 1: Cellular network structure.

$k$ in the area and the subcarrier used for communication is $t$, the expression of the channel gain is

$$
g_{u, t, \mathrm{key}}=\left(-g-m \log _{10} w_{u, k}\right) \vartheta_{u, t, k}+10 \log _{10} l_{u, t, k}
$$

According to Shannon's theorem, the transmission rate $E_{u, k}$ of data transmission between user $U$ and base station $K$ can be obtained, and the calculation expression is

$$
\begin{gathered}
\mathrm{e}_{u, k}=\beta_{k} w_{u} y_{t v y} i p h_{2}\left(1+X_{u, t, k}\right), \\
\mathrm{e}_{u}=\beta_{k} w_{u} \frac{y_{y t}}{o_{t v y}} i p h_{2}\left(1+\delta_{u, t, k}\right), \\
\mathrm{e}_{k}=\chi_{k} \sum_{t=1}^{o_{t v y}} a_{u, t, k} \frac{y_{y t}}{o_{t v y}} i p k_{2}\left(1+\pi_{u, t, k}\right) .
\end{gathered}
$$

In formula (4), $\beta_{k}$ represents the switch state of the $k$ th base station, $y_{y t}$ represents the total bandwidth of the communication model, $o_{t v y}$ represents the total number of communication link subcarriers, and $a_{u, t, k}$ represent user $u$ and base station $k$ using subcarrier $t$ communication.

In the downlink of cellular communication, the interference caused by OFDM technology for information transmission is mainly intercell interference, which is caused by the communication between cells using the same subcarrier. The interference expression is as follows:

$$
\delta_{u, t, k}=\frac{t}{1+o_{0}}=\frac{q_{u, t, k} g_{u, t, k}}{u_{u, t, k}+o_{0}}+\frac{1}{\sum_{x a}\left(x_{0}+y_{0}\right)},
$$

$$
u_{a, t, k}=\sum_{o=1, o \neq k}^{n}\left(\beta_{o} \sum_{g=1}^{o_{k}} a_{g, t, o} g_{u, t, o} q_{u, t, o}+\sum_{s=1, s \neq d}^{w_{u}} a_{u, t, d} q_{w}\right) .
$$

In formula (6), when $a_{g, t, o}=0.5$, it represents the internal interference of the cellular network, which is caused by the communication between the base station $o$ and the user $g$ using the subcarrier $t$ at the same time.

In a wireless communication network, at the same time, the same subcarrier will not cause communication interference unless it is allocated to one user for use, and it will cause severe interference if it is allocated to multiple users or used by $\mathrm{D} 2 \mathrm{D}$ devices at the same time. Therefore,

$$
\sum_{h=1}^{o_{k}} a_{g} a_{t} a_{o}+\sum_{s=1}^{w_{s}} a_{s} a_{t} a_{d} \leq 1
$$

Equation (7) is to ensure that the same subcarrier is allocated only once at the same time to avoid cofrequency interference in the cell.

(2) Base station energy consumption model

In wireless communication networks, operators have long relied on traditional power grids to provide energy. Because traditional power grids produce energy such as carbon dioxide and other greenhouse gas emissions, aggravate the global greenhouse effect, and produce environmental pollutants, clean energy purchased from smart grids is expensive. Therefore, energy harvesting technology has been widely studied, as shown in Figure 2.

It can be seen from Figure 2 that the energy collection technology uses energy collection devices or equipment to collect clean energy such as solar energy, wind energy, and 


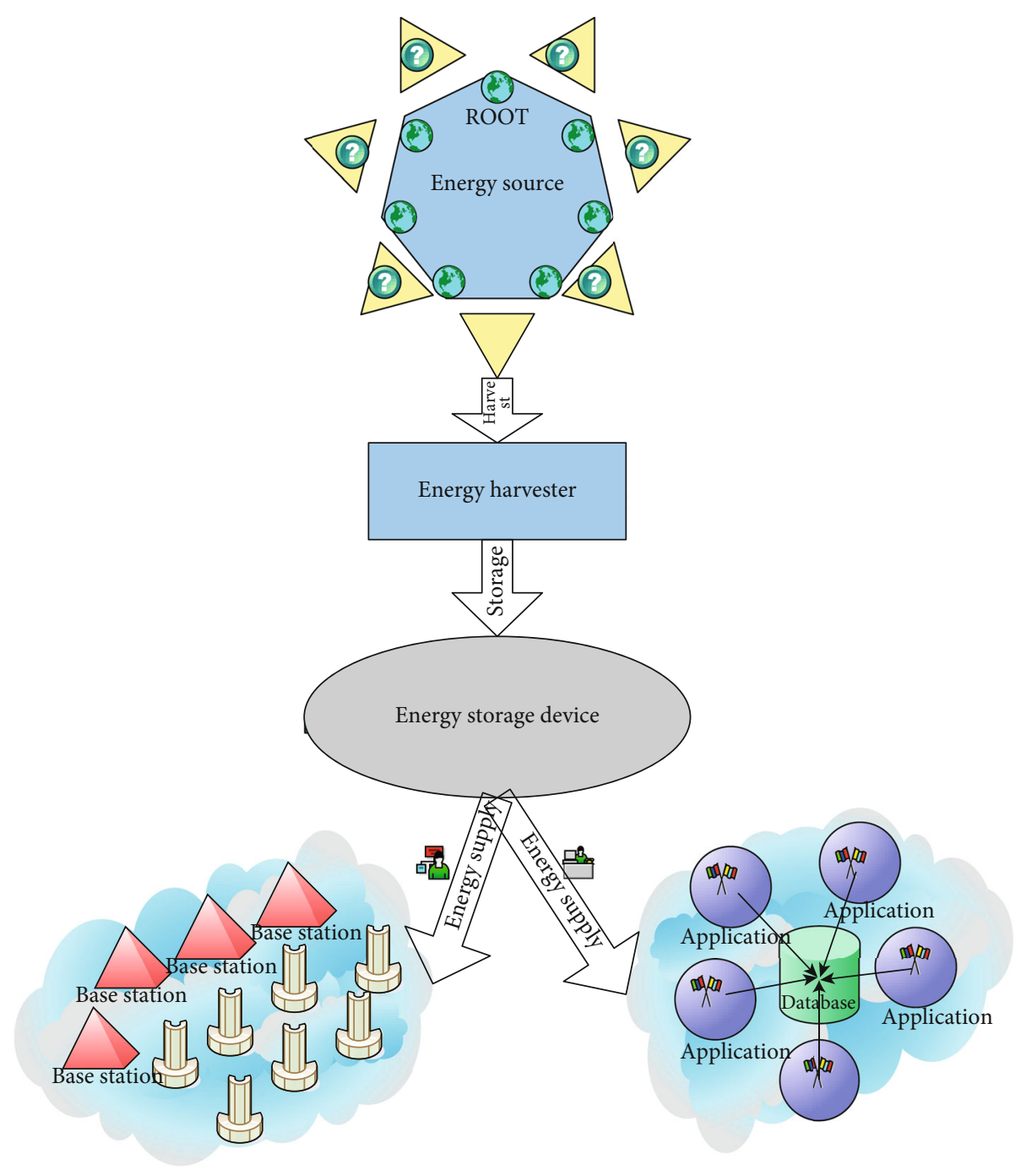

FIGURE 2: Energy harvesting technology.

electromagnetic energy from the surrounding environment or the natural world and convert them into electrical energy for consumption and use by the communication model. Since the base station needs to consume a lot of energy when it is working, in practice, because each base station has a different working state, it consumes different energies, as shown in Equations (8) and (9):

$$
\begin{aligned}
q_{k} & =\sum_{u=1}^{o_{u}} q_{u, t, k}+q_{z, k} \leq q_{\min }, \\
q_{\mathrm{all}} & =\mu \sum_{k=1}^{n} q_{k}+\omega \sum_{g=1}^{o} w_{d}+\pi \sum_{k=1}^{p} f_{v} .
\end{aligned}
$$

In the formula, the coefficient $\mu$ reflects the power amplification factor of the $k$ th base station transmitter.

(3) D2D communication model

In a wireless communication network, when D2D users need to establish a communication connection, they first use spectrum sensing technology to sense the surrounding environment or the spectrum hole of the cell, find the most favorable cellular communication subcarriers for D2D user communication, establish communication between D2D users, connect, release the subcarrier resources only when the D2D user communication is completed, and make full use of the frequency band resources of the cell and dormant cells, as shown in Figure 3.

It can be seen from Figure 3 that the path loss expression between D2D users is as follows:

$$
q i=13.3 i h\left(w_{m, f}\right)+30.2+18 i h\left(l_{z}\right) .
$$

In formula (10), the distance between the $m$ th D2D user and the $f$ th $\mathrm{D} 2 \mathrm{D}$ user is expressed by $w_{m, f}$; due to the short distance of D2D communication, it is mostly used for line-of-sight transmission, and the communication rate is extremely fast. According to Shannon's theorem, the transmission rate of information 


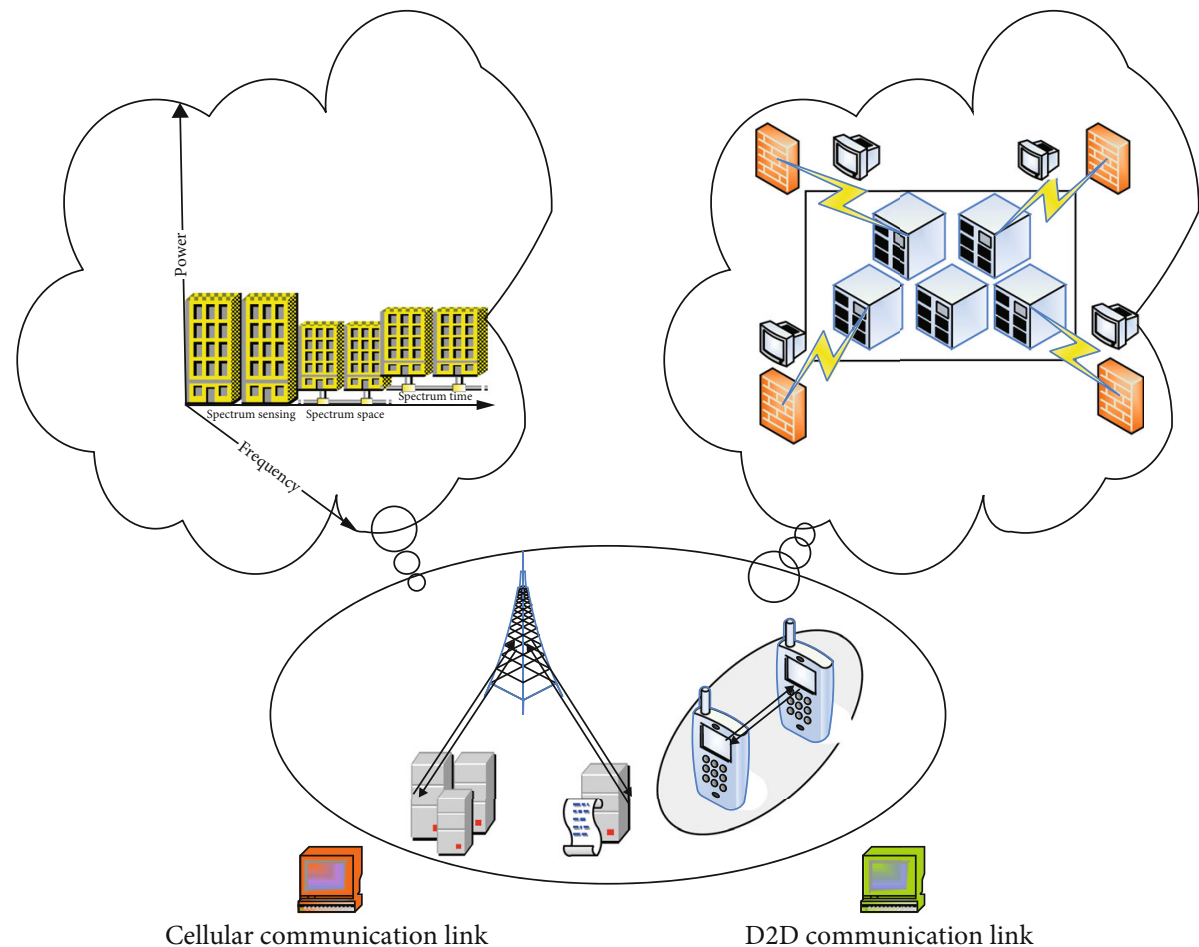

FIgURE 3: Spectrum sensing D2D communication.

transmission between D2D user $m$ and D2D user $f$ using subcarrier $t$ is

$$
e_{m, f}=\sum_{t=1}^{o_{t c y}} a_{m, t, f} \frac{y_{y t}}{o_{t v y}} \log _{2}\left(1+s_{m, t, f}\right), \quad m, f \in 0,1,2, \cdots, w
$$

$$
\mathrm{s}_{m, t, f}=\frac{q_{w}\left|g_{m, t, f}\right|}{u_{m, t, f}+o_{w 0}}+\cap_{k}^{u}(g+1)
$$

In the formula, the transmit power of the D2D user transmitter is represented by $q_{w}, g_{m, t, f}$ represents the path loss of the communication between user $m$ and user $f$ using subcarrier $t$, and $o_{w 0}$ represents the noise power suffered by the communication between the D2D user and the D2D user.

\section{(4) Energy collaboration model}

In a communication network, there are two sources of energy consumed by a base station model. The first is to achieve mutual energy transfer between wireless communication networks through energy cooperation between a large number of base stations. At this time, the base station model does not need to be obtained from the outside world. The second situation is that there is no energy cooperation in the communication network or a very small number of base stations participate in cooperation. When the energy collected by the base station model is not enough to provide the model's own needs, energy needs to be obtained from the traditional power grid, as shown in Figure 4.

It can be seen from Figure 4 that in the energy cooperation mode of the communication network, a new type of energy harvester is installed in each base station model, so that the base station has the ability to collect energy from the natural world. It mainly includes space multiplexing and space diversity. Space diversity is space-time coding that divides data into multiple data substreams and transmits them simultaneously on multiple antennas. The diversity gain is obtained by introducing coding redundancy in the time domain between the transmitting antennas. Spatial multiplexing is to send independent information streams on the transmitting antenna, and the receiving end uses interference suppression methods to decode to maximize the rate. Generally speaking, spatial multiplexing technology can be used to increase the throughput of wireless communication systems, and spatial diversity technology can be used to expand the coverage of wireless communication systems.

In a communication network, if the energy consumed by the $k$ th base station to transmit information per unit time is $m_{k}$ (unit is Joule, J), then $\mathrm{m}_{k}$ can be expressed as

$$
m_{k}=\Delta f_{k}+h_{k}+\sqrt[1]{\frac{1}{2}} \sqrt{\frac{\sum_{k}^{s_{t}}\left(g_{1}+g_{2}+\cdots+g_{m}\right)}{u_{c}}} .
$$

In formula (13), $\Delta f_{k}$ represents the energy obtained by the $k$ th working base station from the energy collector of the wireless communication network, that is, the energy exchange between base station models, and the energy that 


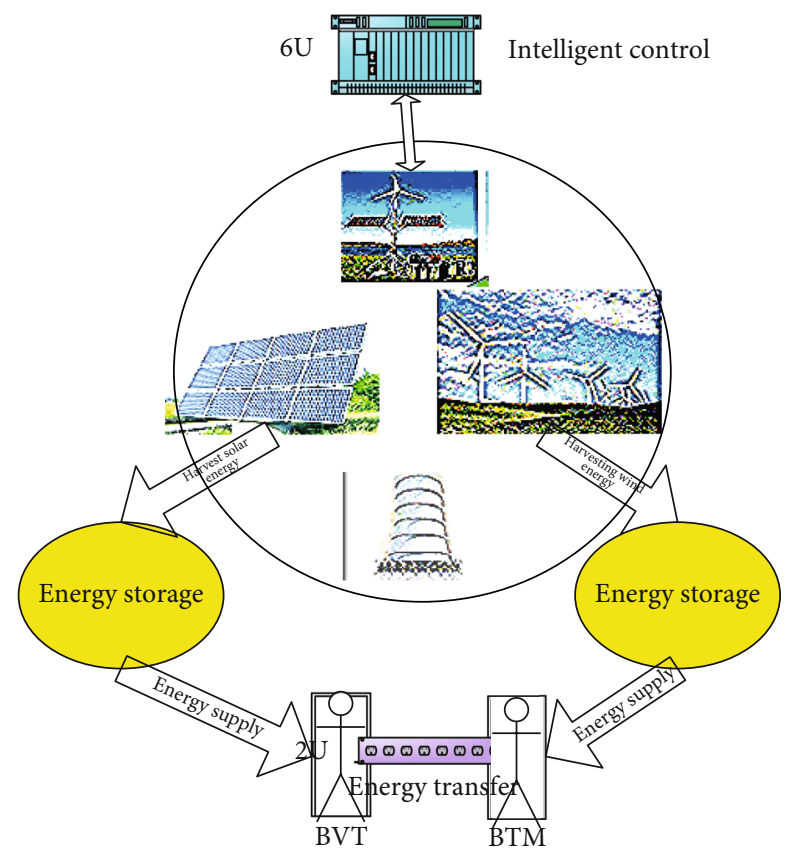

Figure 4: Base station model energy cooperation.

the $k$ th base station needs to obtain from the traditional power grid is represented by $h_{k}$.

\subsection{D Printing Technology and Materials}

(1) Features of 3D printing technology

$3 \mathrm{D}$ printing technology is actually similar to ordinary printing, but it adds an extra dimension to traditional printing. Printed items range from 2 to 3 dimensions. And the raw material for printing is no longer ink, but plastic, metal, etc., which are the building materials in daily life to build objects. It can be said that the process of $3 \mathrm{D}$ printing is the process of manufacturing an object. The manufacturing method is layer-by-layer printing [9-11]. We design the drawings before printing, so that the $3 \mathrm{D}$ printer can print the objects we want step by step according to the drawings after printing starts. The technology used in the printing process is called 3D stereo printing [10].

\section{(2) 3D printed material structure}

There are many materials that can be printed by $3 \mathrm{D}$ printing. They are all building materials in our daily lives. But depending on the nature and usefulness of the materials, the printing techniques used by different materials are not the same. The shapes of objects printed by different technologies are also different. But even so, only the basic units are printed, and all objects printed in 3D are made of these basic units [12-14]. According to different materials, the printing form can be divided into linear, granular, layer, polymer, powder, and surface. $3 \mathrm{D}$ printing also has many technologies in terms of methods. The difference in available materials is the way to distinguish these technologies. Most of them are created by layer institutions to create parts of various parts. Among the materials commonly used in 3D hits are gypsum materials, stainless steel, silver-plated and gold-plated, nylon, rubber-based materials, and stainless steel. According to different materials, it is divided into extrusion type, line type, granular type, powder layer nozzle 3D printing type, lamination type, and photopolymerization type. Among them, the accumulated technology is fused deposition (FDM). The basic materials are thermoplastics, eutectic model metals, and edible materials. In electron beam free forming (EBF), the basic materials are any alloys. The material is any alloy; in electron beam melting (EBM), the basic material is titanium alloy; in selective laser melting molding (SLM), the basic materials are titanium alloy, cobalt chromium alloy, stainless steel, aluminum; in selective thermal sintering (SHS), the basic material is thermoplastic powder; in selective laser sintering (SLS), the basic materials are thermoplastic, metal powder, and ceramic powder. In gypsum $3 \mathrm{D}$ printing $(\mathrm{PP})$, the basic material is gypsum; in layered solid manufacturing (LOM), the basic materials are paper, metal film, and plastic film. In stereographic lithography (SLA), the basic material is light-hardening resin. In digital light processing (DLP), the basic material is light hardening resin [15-17].

\section{(3) 3D printing basic model}

3D printing technology refers to the technology of manufacturing three-dimensional products by adding materials layer by layer through printing equipment based on the established three-dimensional model. This layer-by-layer stacking forming technology is called additive manufacturing. Compared with the traditional manufacturing technology, 3D printing does not need to manufacture molds in advance, does not need to remove a large amount of material during the manufacturing process, and does not need to go through a complex forging process to obtain the final product [18-20]. Therefore, through 3D printing technology, structural optimization, material saving, and energy saving can be achieved in production. 3D printing technology is suitable for rapid prototyping and small batch product manufacturing, manufacturing of complex shapes, and mold design and manufacturing. It is also suitable for the manufacture of difficult-to-machine materials, shape design inspection, assembly inspection, and rapid reaction. Therefore, the 3D printing industry has received more and more extensive attention at home and abroad, and it is bound to become a rising industry with broad development prospects $[21,22]$.

\section{(4) Characteristic structure of 3D printing}

\section{(1) Characteristics of labor allocation}

For a long time, the advantage of labor resources has always been an important prerequisite for the rapid development of China's manufacturing industry. In this case, more and more multinational companies around the world have begun to invest and cooperate in China. Therefore, the 
machinery manufacturing industry has achieved rapid development. However, with the continuous development and progress of science and technology, machinery manufacturing and automation have gradually begun to develop into information and intelligence and no longer need purely manual labor resources. Nowadays, most mechanical manufacturing links rely more on intellectual resources. Based on this, some simple physical labor resources will definitely face unemployment. For a long period of time, China has been short of professional technical personnel resources, which has hindered the smooth development of the machinery manufacturing industry. Mechanical manufacturing and automation technology based on 3D printing technology effectively eliminates the process link, saves most of the traditional procedures, and uses digital production technology as the basis for mechanical manufacturing, which reduces the demand on the assembly line in the past manufacturing process. The usage of $3 \mathrm{D}$ printing in the machinery manufacturing industry has greatly reduced the demand for manual labor. Enterprises often like to adopt more mechanized and automated production processes, which can reduce labor costs. In addition, with the continuous improvement and widespread usage of the representative digital technology such as $3 \mathrm{D}$ printing technology, the problem of idle labor resources will definitely become more and more obvious. Therefore, how to organically combine the idle labor resources required in the traditional machinery manufacturing industry is a key issue that affects the future development of the machinery manufacturing industry [23-25].

\subsubsection{D Stereo Printing Processing and Process}

\section{(1) $3 \mathrm{D}$ printing strategy}

The accuracy of the 3D printing algorithm will affect the final result of 3D printing. It is mainly used to study the preprocessing process of $3 \mathrm{D}$ model files. Among them, the final effect of the final printing is seriously the accuracy of the 3D model itself, so each height information is the most important and accurate information when the model is restored. Generally speaking, 3D modeling is based on height information. The original object is restored, so the height information in it should be valued and accurately restored when modeling, and its accuracy can be guaranteed to be able to restore the objects in it highly. The second point is the accuracy of contour restoration. Generally speaking, we generally use the three-piece surface of slice processing and STL file to approximate the restored model. The slice processing is the initial processing, which plays the role of ups and downs and quickly puts the model into the plane space and uses it for rapid conversion for subsequent operations. Next, we will use the STL file to use a lot of triangles to approximate and restore the original model accurately. Our main requirement is the intersection point, that is, the intersection point of the tangent plane and the triangle edge of the STL file, connecting them into a contour, similar to flat printing.

Both need rasterization and gridding processing. Since the complexity relative to flat printing is still relatively high, it is still lower than flat printing in terms of development and printing, so you can learn from some methods of flat printing when printing. The printing effect can be improved to a certain extent.

(2) Characteristics of 3D stereo printing process

The process of 3D stereo printing can be divided into the following two steps:

(1) The preprocessing phase of 3D modeling

(2) Data preprocessing stage

(3) Preprocessing in 3D printing and rasterizing it. The specific steps are shown in Figure 5

\subsection{Algorithm in 3D Stereo Print Processing}

\section{(1) Collection of 3D height information}

The common method of collecting 3D height information is to use camera projection to collect the fringe information of parallel light on the surface of the object, where $A B$ represents a plane, $C$ point projection light point, projection light transmitted by $C$ point, $C E, C F$, and $C H$. The point at which the projected light intersects the plane we imagine is $E$ , $F$, and $H$, respectively. The $G$ point is the intersection of the $3 \mathrm{D}$ surface and the projected light $C F$. The $M F$ distance is $L$, and the similarity of the triangle can be concluded:

$$
\frac{\mathrm{s}}{L}=\frac{m+h}{h} .
$$

(i) It can be calculated as

$$
h=\frac{m L}{s-L}
$$

According to the above formula, the height information of the corresponding points of all the parallel light projection can be calculated, and the three-bit model can be reduced.

(2) Reconstruction of half-edge topology for hash storage

The hash table is used to store the information of the unwanted triangular surfaces stored in the STL file, collect, organize, and construct the half-side structure according to their set relationship. Thus, the reading efficiency of the 3D model and the contour information of the slice contour are obtained. Topology reconstruction can be divided into three steps:

Get the data: get the relevant information of the triangle grid, and read all the data in the STL file in turn, in order to obtain the storage structure of the triangular surface information of the 3D digital model, such as the three-vertex coordinate information in the triangular surface and the normal vector information therein. 


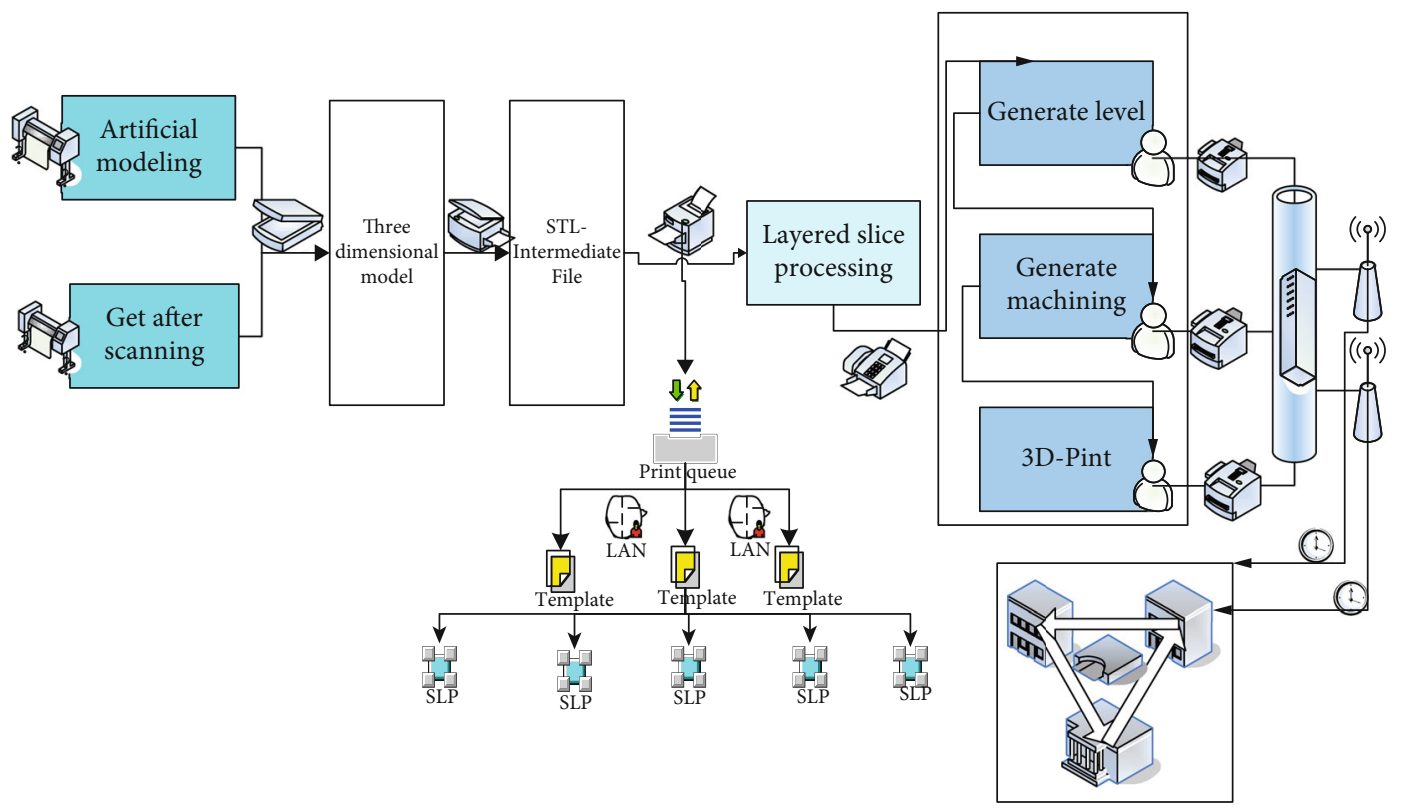

FIGURE 5: Main steps of 3D printing file processing.

According to the topological relation of the half-edge structure, the half-side is found at any point, and the triangular surface is constructed. The spatial relationship between the tangent plane and the adjacent triangular sheet can generally be divided into the above 3 . The common edges of the two adjacent triangular sheets intersect the tangent plane. The common slice planes of the two adjacent triangular facets fall together and intersect each other. The tangent plane does not intersect two adjacent triangle common edges. This triangle has no intersection point and does not count the intersection point.

Using the hash table's storage mode to store the triangular half-edge information: hash table as an additional data structure, at this fixed point of 3D coordinates, we use the node of the hash table as the data structure among them. Because the storage form of triangular slices stored in STL's files is disordered, if you want to establish a more orderly data storage data structure, you need to bubble sort the way to sort multiple times, using the length of the hash table $L$ and the number of triangular slices used $N$ correlation. When the number of times will affect the efficiency of 3D printing and the use of hash storage can make printing easier, reduce complexity to ensure his efficiency.

(3) Its hash function is defined as

$$
\begin{aligned}
\text { Index } & =(\text { int })[(\alpha X+\beta Y+\gamma Z) C+0.5] \delta L, \\
L & =2^{\mathrm{n}}-1, n=\left(\log _{2} N\right)+1, \\
C & =\min \left(C_{1}, C_{2}\right), \\
C_{1} & \leq \frac{2^{32}-1}{\varepsilon_{\max }} \\
C_{2} & =2^{32}-(L+1),
\end{aligned}
$$

TABle 1: Printing parameters.

\begin{tabular}{lcc}
\hline Layer thickness & Nozzle temperature & Printing speed \\
\hline 0.05 & $180^{\circ} \mathrm{C}$ & $5 \mathrm{~mm} / \mathrm{s}$ \\
0.1 & $200^{\circ} \mathrm{C}$ & $10 \mathrm{~mm} / \mathrm{s}$ \\
0.2 & $220^{\circ} \mathrm{C}$ & $15 \mathrm{~mm} / \mathrm{s}$ \\
\hline
\end{tabular}

$$
\varepsilon_{\max }=\alpha X_{\max }+\beta Y_{\max }+\gamma Z_{\max }, \quad \alpha=3, \beta=5, \gamma=7,
$$

$$
X=\frac{1}{2}\left[1+\frac{x}{|x|+k}\right]
$$

Finally : $C \psi=\int_{-\infty}^{+\infty} \frac{|\psi(\mathrm{w})|^{2}}{|\mathrm{w}|} d w \prec \infty$,

where the formulas in $x, y$, and $z$ are obtained by the vertices $x, y$, and $z$, respectively. $K$ take 10 for a while.

\section{Experiment}

3.1. 3D Printing Single-Factor Experiment. Based on the wireless network communication technology to conduct intelligent research on $3 \mathrm{D}$ printing, in order to verify its effectiveness, this paper designs a smart $3 \mathrm{D}$ printing experiment, under the condition that the printing model and printing environment remain unchanged; printing is carried out through wireless network communication. The mobile terminal includes the wireless transmission, and wireless communication module connects with the mobile terminal through the serial port and then transmits the print data to the printer. 


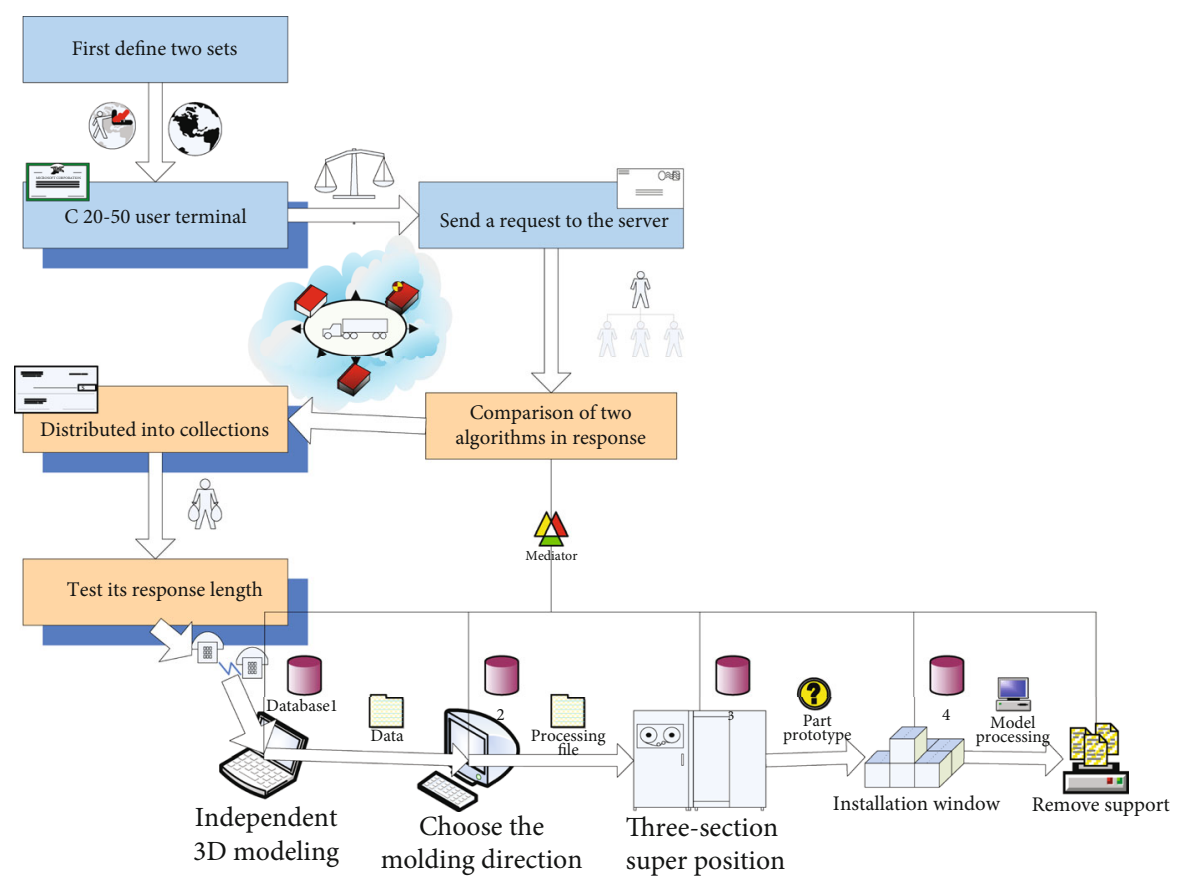

FIgURE 6: Simulation step implementation.

Table 2: Print factor parameters.

\begin{tabular}{lccc}
\hline Experimental groups & Constant factor 1 & Constant factor 2 & Constant factor 3 \\
\hline 1 & Printing speed $15 \mathrm{~mm} / \mathrm{s}$ & Temperature $200^{\circ} \mathrm{C}$ & Layer thickness $0.05 / 0.1 / 0.2 / 0.3 / 0.4 / 0.5 \mathrm{~mm}$ \\
2 & Layer thickness $0.3 \mathrm{~mm}$ & Temperature $200^{\circ} \mathrm{C}$ & Printing speed $5 / 10 / 15 / 20 / 25 / 30 \mathrm{~mm} / \mathrm{s}$ \\
3 & Layer thickness $0.3 \mathrm{~mm}$ & Printing speed $15 \mathrm{~mm} / \mathrm{s}$ & Temperature $180 / 190 / 200 / 210 / 220 / 230^{\circ} \mathrm{C}$ \\
\hline
\end{tabular}

In order to get the optimal printing parameters under the condition of wireless network communication, we adopt the single-factor experiment method in the experiment. We set the time taken for $3 \mathrm{D}$ printing and the size error of the print result as the final index of the experiment. The selected experimental parameters are layer thickness, the speed of printing, and the temperature of the nozzle. Get the basic range values of these parameters under the IoT. Then, these values are averaged as shown in Table 1.

3.2. 3D Printed Orthogonal Experiment. The flow chart of the experiment is shown in Figure 6. This experiment is based on the average value data of the single-factor experiment results of $3 \mathrm{D}$ printing. Also, on the basis of the wireless network communication, examine the effect of two factors on the selected indicators but do not take into account the interaction between factors. The data obtained from the experiment are calculated by interactive algorithm. Consider the effect of thickness, print speed, and nozzle temperature on the final experimental data, and use the wireless network communication algorithm to optimize the parameters and establish the model to confirm the feasibility of $3 \mathrm{D}$ printing automation.

The first step is to establish a three-dimensional model, establish a three-dimensional model of the printed sample through computer modeling software, collect threedimensional data of the target object through a threedimensional laser scanner, and construct, edit, and modify it to generate a three-dimensional digital model in a universal output format. Process the generated three-dimensional model data, and then, add the printing materials to the printer for layer-by-layer printing.

\section{Discussion}

\subsection{Analysis of Experimental Parameters}

(1) On the basis of the wireless network communication, we carried out a single-factor experiment; after data scanning, data sensing, and other $3 \mathrm{D}$ printing basic processes combined with the wireless network communication, we get several sets of print parameters that have been intelligently automatically adjusted. According to the data results, the IoT intelligent automation $3 \mathrm{~d}$ printing model is able to perform intelligent automatic adjustment of parameters, and the obtained parameters are optimized well for the $3 \mathrm{D}$ printing process. In the three groups of experiments required for printing, there were obvious fracture marks when the thickness was $0.05 \mathrm{~mm}$ and 


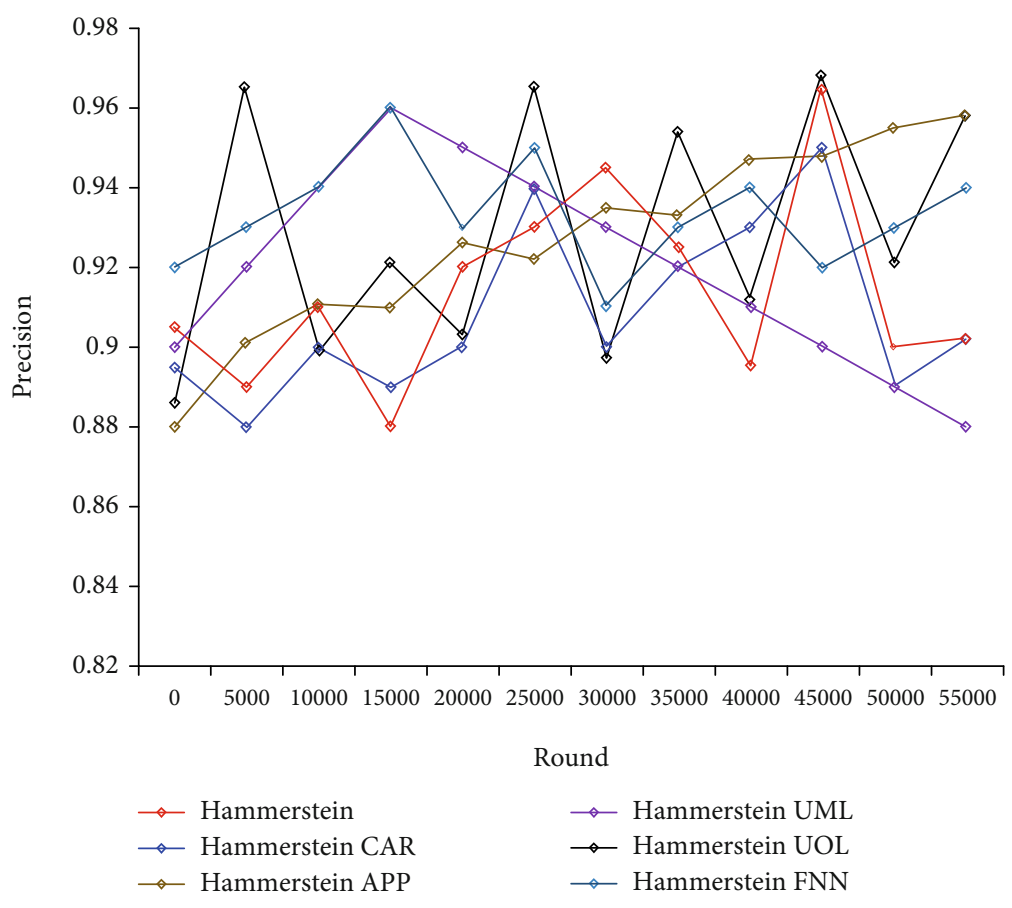

FIgURE 7: Print factor parameters.

$0.1 \mathrm{~mm}$, and 3D was printed when the selected thickness was $0.2 \mathrm{~mm}$. There was no abnormal flow. When the wireless network communication is automatically adjusted, the selected print thickness is $0.3-0.5 \mathrm{~mm}$. In the second group, when the control layer thickness is $0.3 \mathrm{~mm}$ and the temperature is $200^{\circ} \mathrm{C}$, the experimental IoT $3 \mathrm{D}$ printing mechanical printing speed is from $5 \mathrm{~mm} / \mathrm{s}$ to $30 \mathrm{~mm} / \mathrm{s}$, where $5 \mathrm{~mm} / \mathrm{s}$ and $30 \mathrm{~mm} / \mathrm{s}$ appears to have fault phenomenon, while others are normal. The third group experimental control layer thickness is $0.3 \mathrm{~mm}$, the printing speed is $15 \mathrm{~mm} / \mathrm{s}$, and the IoT intelligent model adjusts the temperature at 180/190/200/210/ $220 / 230^{\circ} \mathrm{C}$, abnormal at $230^{\circ} \mathrm{C}$. The rest is printed normally. The IoT intelligent $3 \mathrm{D}$ printing model experimental selection parameters are shown in Table 2 and Figure 7

(2) We obtain the data according to the single-factor experiment; we carry on the average operation, then carry on the orthogonal experiment to these data parameters. We obtained the influence level of three main influencing factors according to the singlefactor experiment. We obtained several optimal results [24], where when the thickness of the layer is $0.2 \mathrm{~mm}$, the printing speed is $10 \mathrm{~mm} / \mathrm{s}$ and the temperature is $190^{\circ} \mathrm{C}$. When the thickness of the layer is $0.2 \mathrm{~mm}$, the printing speed is $10 \mathrm{~mm} / \mathrm{s}$ and the temperature is $190^{\circ} \mathrm{C}$. When the thickness of the layer is $0.3 \mathrm{~mm}$, the printing speed is $15 \mathrm{~mm} / \mathrm{s}$ and the temperature is $200^{\circ} \mathrm{C}$. When the thickness of the layer is $0.4 \mathrm{~mm}$, the printing speed is $20 \mathrm{~mm} / \mathrm{s}$ and the temperature is $210^{\circ} \mathrm{C}$. When the thickness of the layer is $0.5 \mathrm{~mm}$, the printing speed is $25 \mathrm{~mm} / \mathrm{s}$
TABle 3: Main influencing factors and levels of the experiment.

\begin{tabular}{lccc}
\hline $\begin{array}{l}\text { Experimental } \\
\text { groups }\end{array}$ & $\begin{array}{c}\text { Layer } \\
\text { thickness }\end{array}$ & $\begin{array}{c}\text { Printing } \\
\text { speed }\end{array}$ & Temperature \\
\hline 1 & $0.2 \mathrm{~mm}$ & $10 \mathrm{~mm} / \mathrm{s}$ & $190^{\circ} \mathrm{C}$ \\
2 & $0.3 \mathrm{~mm}$ & $15 \mathrm{~mm} / \mathrm{s}$ & $200^{\circ} \mathrm{C}$ \\
3 & $0.4 \mathrm{~mm}$ & $20 \mathrm{~mm} / \mathrm{s}$ & $210^{\circ} \mathrm{C}$ \\
4 & $0.5 \mathrm{~mm}$ & $25 \mathrm{~mm} / \mathrm{s}$ & $220^{\circ} \mathrm{C}$ \\
\hline
\end{tabular}

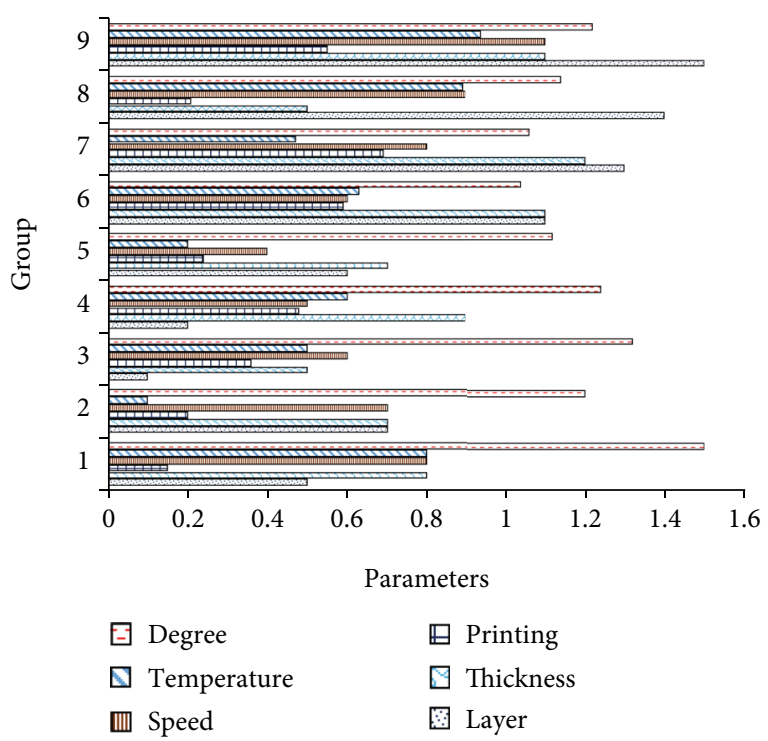

FIGURE 8: Main influencing factors and levels of the experiment. 
TABLE 4: Verified measurement results.

\begin{tabular}{lccccc}
\hline Experimental groups & Printing time & Error value 1 & Error value 2 & Error value 3 & Error value 4 \\
\hline 1 & $308 \mathrm{~s}$ & $0.73 \Delta \%$ & $1.52 \Delta \%$ & $0.96 \Delta \%$ & $1.07 \Delta \%$ \\
2 & $310 \mathrm{~s}$ & $0.69 \Delta \%$ & $1.44 \Delta \%$ & $1.01 \Delta \%$ & $1.12 \Delta \%$ \\
3 & $314 \mathrm{~s}$ & $0.63 \Delta \%$ & $1.37 \Delta \%$ & $0.96 \Delta \%$ & $1.08 \Delta \%$ \\
\hline
\end{tabular}

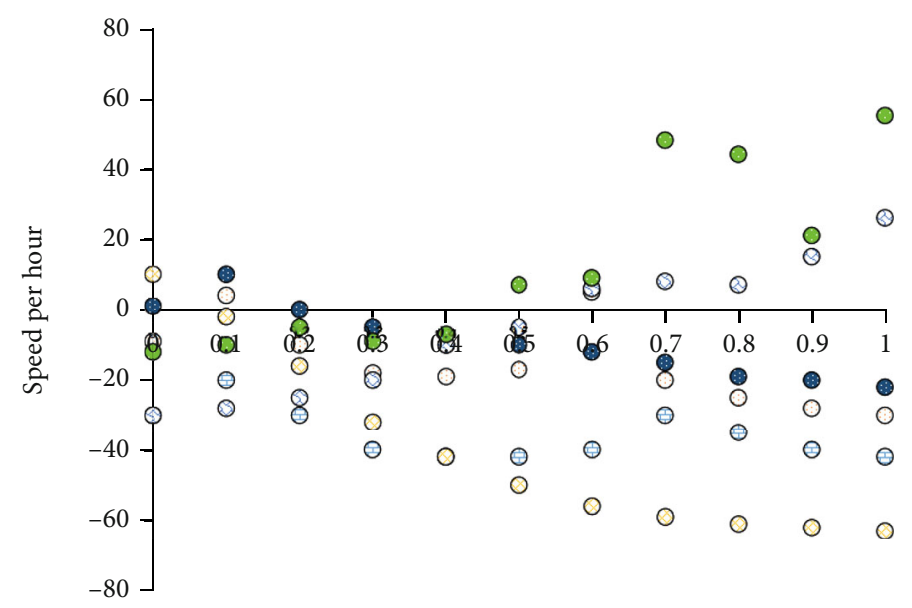

Volume of tasks

$\begin{array}{ll}\odot \text { WRR } & \text { O CPSO-LB } \\ \odot \text { Pick-KX } & \odot \text { Envy-LB } \\ \odot \text { Greedy-LB } & \text { ○ Jury-LB }\end{array}$

Figure 9: Verified measurement results.

and the temperature is $220^{\circ} \mathrm{C}$. This eventually leads to several kinds of automation that can only be set as parameters. After this process, we can greatly improve the time of selecting the printing parameters in $3 \mathrm{D}$ printing and lay the foundation for the realization of intelligent printing, specific as shown in Table 3 and Figure 8

\subsection{Optimal Parametric Data Analysis}

(1) After the single-factor 3D printing experiment, we will integrate the data and carry out the interaction experiment. Through the IoT structure, we can get the optimal solution, the single-factor experiment, and orthogonal experiment study of 3D printing for PLA materials. After the comprehensive analysis of the experimental data, we can draw the following conclusion: the influence degree of each factor on the printing efficiency from big to small is the layer thickness, the printing speed, and the nozzle temperature in turn. With the increase of the layer thickness, the printing time will be shortened, but the printing size difference shows the trend of decreasing first and then increasing, and the size error of the layer thickness at $0.3 \mathrm{~mm}$ is the minimum. As the printing speed increases, the printing time will be shortened, but the printing size error shows a ten- dency to decrease first and then increase, and the size error is minimum when the printing speed is $15 \mathrm{~mm} /$ $\mathrm{s}$, based on the consideration of printing time, and the print size error at $15 \mathrm{~mm} / \mathrm{s}$ and $20 \mathrm{~mm} / \mathrm{s}$ is not much different, so choose the shorter printing time, that is, $20 \mathrm{~mm} / \mathrm{s}$. With the continuous increase of temperature, the printing time changes little, the printing size error shows the trend of decreasing first and then increasing, and the size error is the minimum at $200^{\circ} \mathrm{C}$. Based on the above experimental studies, the optimum parameters were obtained as layer thickness $0.3 \mathrm{~mm}$, printing speed $20 \mathrm{~mm} / \mathrm{s}$, and temperature $200^{\circ} \mathrm{C}$. Results are shown in Table 4 and Figure 9

(2) So in this experiment, the most influential factor on printing time and printing quality is layer thickness, followed by printing speed, and the least influential factor is temperature. At the same time, taking the horizontal coordinates of each factor level and the average value of printing time and average size error as the vertical coordinate, the trend map of each factor and the error of printing time and average size can be drawn. The layer thickness factor can be seen from the trend Figure 6(a); when the thickness of the layer changes between 0.3 and $0.5 \mathrm{~mm}$, the size error becomes higher obviously, and the layer thickness factor is the main factor affecting the printing 
TABle 5: Experimental printing scheme.

\begin{tabular}{|c|c|c|c|c|c|}
\hline Experimental groups & Layer thickness & Printing speed & Temperature & Error value 1 & Error value 2 \\
\hline 1 & $0.2 \mathrm{~mm}$ & $10 \mathrm{~mm} / \mathrm{s}$ & $190^{\circ} \mathrm{C}$ & 0 & 0 \\
\hline 2 & $0.2 \mathrm{~mm}$ & $15 \mathrm{~mm} / \mathrm{s}$ & $200^{\circ} \mathrm{C}$ & 1 & 1 \\
\hline 3 & $0.2 \mathrm{~mm}$ & $20 \mathrm{~mm} / \mathrm{s}$ & $210^{\circ} \mathrm{C}$ & 2 & 2 \\
\hline 4 & $0.2 \mathrm{~mm}$ & $25 \mathrm{~mm} / \mathrm{s}$ & $220^{\circ} \mathrm{C}$ & 3 & 3 \\
\hline 5 & $0.3 \mathrm{~mm}$ & $10 \mathrm{~mm} / \mathrm{s}$ & $190^{\circ} \mathrm{C}$ & 2 & 3 \\
\hline 6 & $0.3 \mathrm{~mm}$ & $15 \mathrm{~mm} / \mathrm{s}$ & $200^{\circ} \mathrm{C}$ & 3 & 2 \\
\hline 7 & $0.3 \mathrm{~mm}$ & $20 \mathrm{~mm} / \mathrm{s}$ & $210^{\circ} \mathrm{C}$ & 0 & 1 \\
\hline 8 & $0.3 \mathrm{~mm}$ & $25 \mathrm{~mm} / \mathrm{s}$ & $220^{\circ} \mathrm{C}$ & 1 & 0 \\
\hline 9 & $0.4 \mathrm{~mm}$ & $10 \mathrm{~mm} / \mathrm{s}$ & $190^{\circ} \mathrm{C}$ & 3 & 1 \\
\hline 10 & $0.4 \mathrm{~mm}$ & $15 \mathrm{~mm} / \mathrm{s}$ & $200^{\circ} \mathrm{C}$ & 2 & 0 \\
\hline 11 & $0.4 \mathrm{~mm}$ & $20 \mathrm{~mm} / \mathrm{s}$ & $210^{\circ} \mathrm{C}$ & 1 & 3 \\
\hline 12 & $0.4 \mathrm{~mm}$ & $25 \mathrm{~mm} / \mathrm{s}$ & $220^{\circ} \mathrm{C}$ & 0 & 2 \\
\hline 13 & $0.5 \mathrm{~mm}$ & $10 \mathrm{~mm} / \mathrm{s}$ & $190^{\circ} \mathrm{C}$ & 1 & 2 \\
\hline 14 & $0.5 \mathrm{~mm}$ & $15 \mathrm{~mm} / \mathrm{s}$ & $200^{\circ} \mathrm{C}$ & 0 & 3 \\
\hline 15 & $0.5 \mathrm{~mm}$ & $20 \mathrm{~mm} / \mathrm{s}$ & $210^{\circ} \mathrm{C}$ & 3 & 0 \\
\hline 16 & $0.5 \mathrm{~mm}$ & $25 \mathrm{~mm} / \mathrm{s}$ & $220^{\circ} \mathrm{C}$ & 2 & 1 \\
\hline
\end{tabular}

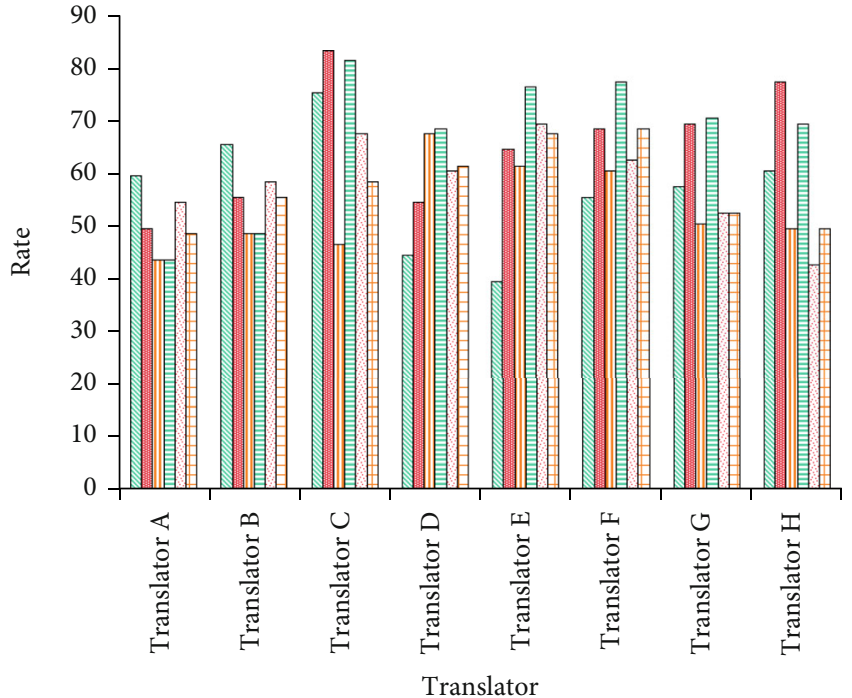

Satisfaction in translation

Improved translators

Ways of translation

FIGURE 10: Experimental printing scheme.

quality, which should be considered in determining the optimal level. So the layer thickness selection is $0.3 \mathrm{~mm}$. In the print speed factor: as can be seen from Figure 6(b), when the printing speed is at $15 \mathrm{~mm} / \mathrm{s}$ and $20 \mathrm{~mm} / \mathrm{s}$, the printing quality is not much different; for the consideration of shortening the printing time, the higher speed is preferred. So print speed selected is $20 \mathrm{~mm} / \mathrm{s}$. In the temperature factor: from Figure 6(c), it can be seen that the influence of temperature on printing time is very small, but it has obvious influence on the error of printing size, and the error of printing size at $200^{\circ} \mathrm{C}$ is minimal. So the temperature is selected at $200^{\circ} \mathrm{C}$. Specific data and trends are shown in Table 5 and Figure 10

\section{Conclusions}

The era of big data promotes the continuous development of wireless communication. User experience rate, traffic density, end-to-end delay, peak communication rate, connection density, and user mobility have become key technical indicators of a new generation of wireless communication. In order to improve communication network capacity and user experience rate, wireless communication networks need to deploy higher density cell base stations to provide information transfer and intelligent control for user communication. On this basis, large-scale smart devices and mobile terminals can access the network at high speed anytime and anywhere. Moreover, the intelligent 3D printer under the wireless communication network can solve the problem of automatic adjustment of printing parameters and reduce the damage rate, error, and loss of materials. Compared with traditional $3 \mathrm{D}$ printing, it will not increase the cost due to the complexity of the manufactured items and can achieve one type of manufacturing; reduce waste by-products, etc.; effectively shorten the manufacturing cost and time of complex molds; and promote the development of traditional manufacturing in the direction of intelligence and digitalization; smart 3D printing technology based on wireless network communication can better meet the needs of contemporary technological development.

Due to the high accuracy and hardware requirements of $3 \mathrm{D}$ printing, if there is no scientific and effective intelligent printing scheme, it is difficult to drive the development of this technology. Wireless network communication technology can be a good help to achieve this. Using the unique RFID technology, it can help identify the print target; after 
intelligent sensing, it can adjust the print status and parameters continuously and quickly in real time. In addition, the wireless network communication transmission is reliable and stable; with the Internet and wireless network support, all the required information is real-time and accurate and has secure transmission to the print terminal and the front end. The most important point is that the wireless network communication can be an intelligent process in the acquired and scanned data, to achieve intelligent control and detection and really help to achieve intelligent automation.

Contemporary science and technology are booming; 3D printing and wireless network communication structures have spawned one after another. Our requirements for high quality and efficiency are constantly increasing and rising. Faced with this situation, we are also constantly adjusting and adjusting various scientific technologies to adapt to the current rhythm of scientific life. The purpose of this article is to study the use of $3 \mathrm{D}$ printing technology to build the technology or digital model based on the wireless network communication technology to improve the efficiency of mechanical manufacturing and achieve automation and intelligence. By constructing an experimental model, the error size during 3D printing is analyzed and corrected, and the process parameters during printing are analyzed. Through the wireless network communication to adjust the basic parameters such as layer thickness, printing speed, and temperature, the basic experimental methods, orthogonal experiments, and single-factor experiments are used to study each influencing factor during automatic printing to obtain the optimal parameter combination. Experiments show that with the support of the hardware and data of the wireless network communication, the timeliness and quality of $3 \mathrm{D}$ printing can be significantly improved. These are the basis for realizing 3D printing automation and intelligence. The experimental data shows that the intelligent automated $3 \mathrm{D}$ printing machinery of the wireless network communication adjusts the $3 \mathrm{D}$ printing parameters through the wireless network communication technology; combined with intelligent real-time monitoring and sensing equipment, the efficiency of 3D printing machinery printing is increased by about $15 \%$, and the economic cost is saved by about $20 \%$ It has guiding significance for the development of intelligent automated 3D printing machinery for the wireless network communication.

\section{Data Availability}

No data were used to support this study.

\section{Conflicts of Interest}

The authors declare that they have no conflicts of interest.

\section{Acknowledgments}

This work was supported by the Zhejiang Provincial Key Research and Development Project (No. 2021C05006).

\section{References}

[1] T. Duda and L. V. Raghavan, "3D metal printing technology," IFAC-PapersOnLine, vol. 49, no. 29, pp. 103-110, 2016.

[2] A. H. Loo, C. K. Chua, and M. Pumera, "DNA biosensing with 3D printing technology," Analyst, vol. 142, no. 2, pp. 279-283, 2017.

[3] A. Vanderploeg, S. E. Lee, and M. Mamp, "The application of 3D printing technology in the fashion industry," International Journal of Fashion Design, Technology and Education, vol. 10, no. 2, pp. 170-179, 2017.

[4] A. M. A. Abu znaid, M. Idris, A. Wahab, L. K. Qabajeh, and O. A. Mahdi, "Low communication cost (LCC) scheme for localizing mobile wireless sensor networks," Wireless Networks, vol. 23, no. 3, pp. 737-747, 2017.

[5] Y. Long, J. Pan, Q. Zhang, and Y. Hao, “3D printing technology and its impact on Chinese manufacturing," International Journal of Production Research, vol. 55, no. 5, pp. 1488-1497, 2017.

[6] G. W. Ma, L. Wang, and Y. Ju, "State-of-the-art of 3D printing technology of cementitious material-an emerging technique for construction," SCIENCE CHINA Technological Sciences, vol. 61, no. 4, pp. 475-495, 2018.

[7] B. G. Ibrahimov, M. Q. Hasanov, R. T. Humbatov, and R. F. Ibrahimov, "Research on the performance of intelligent communication networks," IFAC-PapersOnLine, vol. 51, no. 30, pp. 768-770, 2018.

[8] A. K. Au, N. Bhattacharjee, L. F. Horowitz, T. C. Chang, and A. Folch, "3D-printed microfluidic automation," Lab on a Chip, vol. 15, no. 8, pp. 1934-1941, 2015.

[9] L. Tong, X. Zhu, H. M. Georges, Z. Luo, and W. Dong, "Performance analysis of co- and cross-tier device-to-device communication underlaying macro-small cell wireless networks," KSII Transactions on Internet and Information Systems, vol. 10, no. 4, pp. 1481-1500, 2016.

[10] I. Hager, A. Golonka, and R. Putanowicz, "3D printing of buildings and building components as the future of sustainable construction?," Procedia Engineering, vol. 151, no. 151, pp. 292-299, 2016.

[11] B. Luo and Z. Sun, "Enabling end-to-end communication between wireless sensor networks and the internet based on 6LoWPAN," Chinese Journal of Electronics, vol. 24, no. 3, pp. 633-638, 2016.

[12] M. Kamran and A. Saxena, "A comprehensive study on 3D printing technology," MIT International Journal of Mechanical Engineering, vol. 6, no. 2, pp. 63-69, 2016.

[13] M. Scholze, A. Singh, P. F. Lozano et al., "Utilization of 3D printing technology to facilitate and standardize soft tissue testing," Scientific Reports, vol. 8, no. 1, article 11340, 2018.

[14] T. Yang, S. Lin, Q. Xie et al., "Impact of 3D printing technology on the comprehension of surgical liver anatomy," Surgical Endoscopy, vol. 33, no. 2, pp. 411-417, 2019.

[15] T. Duda and L. V. Raghavan, "3D metal printing technology: the need to re-invent design practice," AI \& Society, vol. 33, no. 2, pp. 241-252, 2018.

[16] T. Yang, S. Lin, T. Tan et al., "Impact of 3D printing technology on comprehension of surgical anatomy of retroperitoneal tumor," World Journal of Surgery, vol. 42, no. 8, pp. 23392343, 2018. 
[17] S. A. Kale, "Smart integrated approach for future E-commerce jewelry business using 3D printing," E-Commerce for future \& Trends, vol. 6, no. 1, pp. 83-90, 2019.

[18] E. E. Cho, H. H. Hein, and Z. Lynn, "Investigation on influence of infill pattern and layer thickness on mechanical strength of PLA material in 3D printing technology," J. Eng. Sci. Res., vol. 3, no. 2, pp. 27-37, 2019.

[19] P. Ahlholm, K. Sipilä, P. Vallittu, U. Kotiranta, and R. Lappalainen, "Accuracy of inlay and onlay restorations based on 3D printing or milling technique-a pilot study," The European Journal of Prosthodontics and Restorative Dentistry, vol. 27, no. 2, pp. 56-64, 2019.

[20] Z. Liu, Y. Wang, B. Wu, C. Cui, Y. Guo, and C. Yan, “A critical review of fused deposition modeling $3 \mathrm{D}$ printing technology in manufacturing polylactic acid parts," The International Journal of Advanced Manufacturing Technology, vol. 102, no. 9-12, pp. 2877-2889, 2019.

[21] S. Li, W. Duan, T. Zhao et al., "The fabrication of SiBCN ceramic components from preceramic polymers by digital light processing (DLP) 3D printing technology," Journal of the European Ceramic Society, vol. 38, no. 14, pp. 4597-4603, 2018.

[22] B. Özdemir, K. Yayla, and S. Burmaoğlu, "Diffusion of 3D printing technology," International Journal of KnowledgeBased Organizations, vol. 9, no. 3, pp. 33-47, 2019.

[23] P. Holzmann, E. J. Schwarz, and D. B. Audretsch, "Understanding the determinants of novel technology adoption among teachers: the case of 3D printing," The Journal of Technology Transfer, vol. 45, no. 1, pp. 259-275, 2020.

[24] S. A. Lurie, Y. O. Solyaev, L. N. Rabinskiy, P. O. Polyakov, and I. Sevostianov, "Mechanical behavior of porous Si3N4 ceramics manufactured with 3D printing technology," Journal of Materials Science, vol. 53, no. 7, pp. 4796-4805, 2018.

[25] Y. Huang, D. Zhu, Y. Qian et al., "A hybrid method to trace technology evolution pathways: a case study of 3D printing," Scientometrics, vol. 111, no. 1, pp. 185-204, 2017. 